\title{
Compreensão literal e inferencial em alunos do Ensino Fundamental
}

\author{
Literal and inferential comprehension in Fundamental Education students
}

\author{
Danielle Baretta \\ Vera Wannmacher Pereira \\ Pontifícia Universidade Católica do Rio Grande do Sul - PUC/RS - Porto Alegre - Rio Grande do Sul - Brasil
}

\begin{abstract}
Resumo: Apoiado em fundamentos psicolinguísticos, o presente artigo trata sobre a leitura com foco na compreensão de informações literais e inferenciais. Para tanto, foi realizada uma pesquisa envolvendo alunos do 6ㅇ e 7ํㅡㅁ anos do Ensino Fundamental de uma escola pública federal da cidade de Porto Alegre. A compreensão da leitura foi avaliada por meio de um questionário contendo seis perguntas abertas, sendo três literais e três inferenciais. A tarefa foi realizada com base na leitura de um texto narrativo literário. Os resultados demonstraram que as perguntas inferenciais foram mais difíceis de responder do que as perguntas literais tanto para os alunos do $6^{\circ}$ quanto do $7^{\circ}$ ano, sugerindo que realizar inferências é uma tarefa complexa para alunos nos níveis de escolaridade investigados. Os dados revelaram haver diferenças significativas entre os dois grupos de participantes com relação ao estabelecimento de inferências, indicando que esta capacidade evolui com a progressão escolar. Além disso, conforme mostram os resultados, o tipo de inferência e o modo como a informação literal é apresentada no texto também influencia na compreensão.
\end{abstract}

Palavras-chave: compreensão leitora; informações literais; informações inferenciais; Ensino Fundamental.

Abstract: Based on psycholinguistic foundations, the present article deals with reading with a focus on the comprehension of literal and inferential information. For that, a research was carried out involving students of the 6th and 7th years of elementary school in a federal public school in the city of Porto Alegre. The reading comprehension was evaluated by a questionnaire containing six open questions, three literals and three inferences. The task was carried out based on the reading of a literary narrative text. The results showed that the inferential questions were more difficult than the literal questions for both the 6th and 7th grade students, suggesting that inferences are a complex task for students at the levels of schooling investigated. The data revealed that there were significant differences between the two groups of participants regarding the establishment of inferences, indicating that this ability evolves with school progression. In addition, as the results show, the type of inference and how literal information is presented in the text also influences comprehension.

Keywords: reading comprehension; literal information; inferential information; Elementary School. 


\section{Introdução}

Provas oficiais que analisam o desempenho em leitura dos estudantes constatam que os índices alcançados pelos alunos brasileiros são insatisfatórios. Segundo relatório da Organização para Cooperação e Desenvolvimento Econômico (OCDE) de 2016, em 2015, o desempenho em leitura dos estudantes brasileiros piorou em relação a 2012. De acordo com dados do Programa Internacional de Avaliação de Alunos (PISA), o país somou 407 pontos em leitura, três a menos do que sua pontuação na avaliação anterior, sendo que a média dos países avaliados foi de 493 pontos. Com isso, o Brasil ficou na 59a posição no ranking de leitura.

O relatório destaca, ainda, que mais da metade (50,99\%) dos alunos brasileiros não alcança o nível 2 de desempenho na avaliação que tem o nível 7 como teto. Isso significa que eles não são capazes de reconhecer a ideia principal de um texto, realizar inferências elementares, entender as relações ou interpretar o significado dentro de uma parte delimitada do texto e estabelecer comparações ou conexões entre o texto e conhecimentos externos.

Esses resultados indicam a preocupante condição de compreensão leitora dos estudantes do Ensino Fundamental e Médio e revelam o quadro caótico em que se encontra o ensino de leitura nas escolas brasileiras, ainda dominado por práticas pedagógicas ultrapassadas. Estudo realizado por Marcuschi (2008), que analisou exercícios de compreensão leitora de diversos livros didáticos adotados no Ensino Fundamental em escolas da cidade de Recife, mostrou que a maior parte das atividades exigia do aluno a cópia de trechos literais do texto e que somente $5 \%$ das perguntas requeriam o estabelecimento de relações e inferências.

Diante desse quadro, é visível a necessidade de se repensarem as práticas de leitura na escola, revendo as estratégias adotadas. Nesse sentido, pesquisadores de diversas áreas têm voltado seus esforços para entender como os estudantes leem, tentando chegar à raiz do problema de compreensão que enfrentam nossos alunos. Nesse entendimento, está sendo desenvolvido, com o apoio da FAPERGS, um projeto de âmbito internacional, sob a coordenação da Profa. Dra. Vera Wannmacher Pereira, cujo objetivo é investigar a compreensão leitora de alunos do $4^{\circ}$ ano do Ensino Fundamental ao $3^{\circ}$ ano do Ensino Médio. O estudo aqui relatado insere-se nesse projeto e tem como objetivo verificar como alunos do $6^{\circ}$ e $7^{\circ}$ anos do Ensino Fundamental compreendem informações literais e inferenciais de um texto narrativo.

\section{Fundamentação teórica}

$\mathrm{Na}$ concepção cognitivista, a leitura é considerada uma prática de construção de sentidos e seu produto primário é a compreensão. Spinillo (2013) comenta que a reflexão sobre a compreensão de textos deve considerar três instâncias: o leitor, o texto e a interação entre eles. A compreensão, para a autora, deriva da relação entre o leitor que, durante a leitura, aciona um conjunto de habilidades cognitivas, e o texto, escrito sob certa forma linguística e com um propósito comunicativo específico, inseridos em uma determinada situação. Essas instâncias caracterizam, segundo a autora, as três dimensões que envolvem a compreensão: a dimensão social, a linguística e a cognitiva. A primeira diz respeito ao conhecimento sociocultural, às expectativas e objetivos de leitura em determinado contexto social. A segunda, por sua vez, refere-se à materialidade linguística do texto que se constitui no nível da palavra, da sentença e do texto como um todo. A última supõe aspectos relativos ao processamento das informações, tais como a memória, o monitoramento e as inferências.

Nesse processo, o leitor, a partir das informações disponíveis no texto, seleciona aquelas que considera mais relevantes tendo em vista seus objetivos de leitura. Essas informações ativam, em sua memória, o conhecimento prévio que possui sobre $o$ assunto, permitindo-lhe integrar o dado novo ao já existente e, assim, construir o sentido do texto.

A leitura, portanto, não é um processo passivo no qual o leitor extrai sentidos do texto a partir do reconhecimento das intenções do autor ou do 
reconhecimento das palavras e estruturas do texto. $\mathrm{Na}$ realidade é a interação entre todos esses elementos que resultará na compreensão do sentido do texto. É por isso que Kato (2007, p. 72) afirma que o texto é "um conjunto de pegadas a serem utilizadas para recapitular as estratégias do autor e através delas chegar aos seus objetivos". Isso significa que, embora não se possa falar em um sentido único do texto, também não se pode considerar que toda interpretação é possível, pois para que a compreensão seja efetiva é necessário que as hipóteses e inferências realizadas pelo leitor encontrem amparo na materialidade do texto.

Marcuschi (2008) ilustra esse aspecto valendose da metáfora criada por Dascal, que imagina o texto como uma cebola. Segundo o autor, as camadas internas representam as informações objetivas, elementos tipicamente informacionais do texto e que não são passíveis de interpretações diversas, como nomes, lugares etc. A camada intermediária, por sua vez, é o terreno das inferências, isto é, das diferentes, porém válidas leituras. A camada mais externa é a mais sujeita a equívocos, pois consiste no domínio de nossas crenças e valores. É nesse domínio que surgem as extrapolações, os sentidos não autorizados pelo texto.

Esse processo de construção do sentido durante a leitura ocorre por meio de dois tipos básicos de processamento da leitura: o processamento ascendente e o processamento descendente (LEFFA, 1996; SOLÉ, 1998; KATO, 2007; SCLIAR-CABRAL, 2008).

O processamento ascendente enfatiza o texto e as informações nele presentes como ponto de partida para a compreensão. Nesse tipo de processamento, o leitor parte das unidades menores para as maiores. Todas as pistas visuais são utilizadas para, a partir do reconhecimento de palavras, frases, orações compor um todo até chegar à compreensão. A leitura é considerada um processo passivo, cabendo ao leitor decodificar o que está no texto, sem considerar a importância do contexto. Sendo assim, segundo Solé (1998), as propostas de ensino baseadas nesse modelo centram sua atenção no desenvolvimento de habilidades de decodificação, pois consideram que o leitor pode compreender 0 texto simplesmente porque pode decifrá-lo totalmente.

No processamento descendente, por sua vez, o leitor parte do seu conhecimento prévio, seja ele linguístico ou extralinguístico, para atribuir sentido ao texto, realizando antecipações sobre a leitura. Ao contrário da abordagem ascendente, o modelo descendente coloca o leitor no centro do processo de leitura, uma vez que o sentido é construído a partir do conhecimento que o leitor traz consolidado na memória. Para Goodman (1976, p. 12), um dos precursores dessa abordagem, a leitura é "um processo psicolinguístico que começa com uma representação linguística codificada pelo escritor e termina com o significado construído pelo leitor".

De acordo com Kato (2007) esses dois tipos de processamento caracterizam diferentes tipos de leitores. O leitor que privilegia o processamento descendente apreende facilmente as ideias gerais e principais do texto, é fluente e veloz, porém faz uso excessivo de adivinhações, utilizando mais seu conhecimento prévio do que as informações veiculadas no texto. $O$ leitor que utiliza 0 processamento ascendente, por outro lado, constrói o significado com base nos dados do texto, detém-se em detalhes, fazendo pouca leitura nas entrelinhas. É vagaroso e pouco fluente e apresenta dificuldade para sintetizar as ideias do texto por não saber diferenciar o que é mais relevante. No entanto, é um leitor que, ao contrário do leitor que usa o modelo descendente, não tira conclusões apressadas.

Castro e Pereira (2004) alertam que, no processamento da leitura, o leitor não pode apenas considerar seu conhecimento prévio sem basear-se nos elementos linguísticos do texto (processo descendente), pois correria o risco de construir um sentido equivocado, que não encontra suporte no texto. Igualmente, não pode considerar somente os elementos linguísticos, sem relacioná-los com o que já conhece sobre o conteúdo (processo ascendente), pois, para relacionar as informações em nível local (palavras, frases e sentenças) e global (texto como 
um todo), elas precisam estar integradas ao conhecimento prévio do leitor.

Esses dois tipos de processamentos, portanto, não são excludentes, mas complementares, uma vez que, como afirma Leffa (1996), a leitura implica correspondência entre o conhecimento prévio do leitor e os dados do texto, gerando novos conhecimentos. Dessa concepção, provém um terceiro tipo de processamento: o interativo, que combina características dos outros dois modelos.

No processamento interativo, o foco não está nem no leitor, nem no texto, mas na interação entre os conhecimentos já construídos pelo leitor e os dados apresentados pelo texto. Nesse processo, o leitor faz perguntas a partir de seu conhecimento linguístico, textual e de mundo. Para respondê-las, deverá buscar no texto as pistas que sustentarão ou não suas hipóteses. A compreensão ocorre quando essas perguntas são respondidas (SMITH, 2003).

Um dos modelos interativos de maior aceitação na literatura, o Modelo de Construção-Integração de Kitsch (1998) considera a compreensão um processo inferencial por natureza. Esse modelo consiste em duas dimensões que se relacionam entre si: o texto base, uma representação mental construída a partir de informações explicitadas no texto; e o modelo situacional, uma representação mental realizada a partir do conhecimento prévio do leitor na qual as lacunas do texto são preenchidas por meio do estabelecimento de inferências. O modelo é considerado interativo, pois prevê que, durante a leitura, o leitor integre os elementos do texto-base para, desse modo, construir a representação mental do texto, relacionando informações no nível intratextual e extratextual.

\section{Metodologia}

\subsection{Participantes}

Participaram da pesquisa 40 estudantes de classe média, com idades entre 10 e 13 anos, frequentando o Ensino Fundamental de uma escola pública federal da cidade de Porto Alegre/RS. Destes,

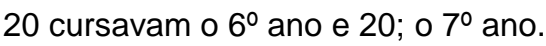

\subsection{Materiais e procedimentos}

A compreensão da leitura foi avaliada por meio de um questionário contendo seis perguntas abertas, sendo três literais e três inferenciais. As seis perguntas que compõem 0 instrumento estão distribuídas conforme descrito na tabela 1.

\section{Tabela 1 - Distribuição das perguntas do questionário}

\begin{tabular}{cl}
\hline |tem do questionário & Tipo de pergunta \\
\hline Pergunta de número $1(\mathrm{P} 1)$ & Inferencial \\
Pergunta de número $2(\mathrm{P} 2)$ & Literal \\
Pergunta de número $3(\mathrm{P} 3)$ & Literal \\
Pergunta de número $4(\mathrm{P} 4)$ & Inferencial \\
Pergunta de número $5(\mathrm{P} 5)$ & Literal \\
Pergunta de número $6(\mathrm{P} 6)$ & Inferencial \\
\hline
\end{tabular}

A tarefa foi realizada com base na leitura de um texto narrativo literário. Para a seleção do texto considerou-se a extensão, a adequação do conteúdo e a qualidade estilística. Além disso, buscou-se um texto que permitisse averiguar a realização de inferências pelos participantes. Desse modo, o texto selecionado apresentou-se como uma escolha bastante pertinente, uma vez que o desfecho da história é construído a partir de informações implícitas, cuja compreensão depende essencialmente da realização de inferências. Para torná-lo mais apropriado, foram feitas adaptações em determinadas estruturas, aproximando-as ao universo linguístico do público alvo da pesquisa.

Neste estudo, optou-se por fazer a coleta de dados por meio de perguntas abertas em lugar de itens de múltipla escolha, mais comumente utilizados em instrumentos que avaliam a compreensão leitora. Essa medida foi adotada tendo em vista o fato de que tarefas de múltipla escolha podem estar sujeitas a efeitos de processos de adivinhação ou uso de estratégias compensatórias por parte dos 
respondentes, como a eliminação de alternativas menos prováveis, além de poder levar a inferências não realizadas durante a leitura (SOUSA e HÜBNER, 2015).

Para a coleta dos dados, foi solicitado aos participantes que lessem o texto silenciosamente. FoiIhes informado que, posteriormente, deveriam responder a questões sobre o conteúdo lido. Os participantes puderam permanecer com o texto durante a realização da tarefa a fim de evitar sobrecarga da memória de trabalho que pudesse interferir nos dados.

$\mathrm{Na}$ avaliação das respostas ao questionário, foram pontuadas separadamente as respostas às perguntas literais $\mathrm{e}$ as respostas às perguntas inferenciais. Para cada tipo de questão, o participante poderia alcançar o máximo de três pontos.

Para examinar a significância das diferenças entre os escores por tipo de pergunta utilizou-se o teste $T$ Student. Adotou-se o nível de significância de $5 \%(0,05)$ para a aplicação dos testes estatísticos.

\section{Resultados e discussão}

O teste $T$ Student detectou diferenças significativas entre as perguntas literais e inferenciais nos dois grupos analisados. Como pode ser visto na tabela 2, em ambos os grupos, as perguntas literais apresentaram um percentual de respostas corretas mais alto que as perguntas inferenciais. Isso mostra que realizar inferências é uma tarefa que oferece dificuldades para alunos nos níveis de escolaridade investigados. Esse fato tem sido documentado pela literatura (YUILL e OAKHILL, 1991).

Tabela 2 - Porcentagem de acerto por tipo de pergunta

\begin{tabular}{ccc}
\hline Tipo de pergunta & Grupo 1 (n=60) & Grupo 2 (n=60) \\
\hline $\begin{array}{c}\text { Literal } \\
\text { Inferencial }\end{array}$ & $49(81,7 \%)$ & $52(86,7 \%)$ \\
& $32(53,3 \%)$ & $43(71,7 \%)$ \\
\hline
\end{tabular}

Nota: Grupo 1: alunos do 6ํㅜ do Ensino Fundamental

Grupo 2: alunos do 7º ano do Ensino Fundamental
$\mathrm{Na}$ tabela 3 constam os valores de significância relativos aos tipos de pergunta examinadas pelo teste estatístico.

Tabela 3 - Valores de significância do teste $T$ Student (pareado) em relação aos tipos de pergunta

\begin{tabular}{ccc}
\hline & \multicolumn{3}{c}{ Literais vs. Inferenciais } \\
\hline Grupos & sd & Valor-p \\
\hline Grupo 1 & 0,9880869 & $0,001086325^{\star}$ \\
Grupo 2 & 0,7591547 & $0,01576959^{\star}$ \\
\hline
\end{tabular}

Nota: Grupo 1: alunos do 6º do Ensino Fundamental

Grupo 2: alunos do $7^{\circ}$ ano do Ensino Fundamental

Comparações entre os grupos revelaram que as respostas corretas às perguntas inferenciais eram significativamente mais frequentes no Grupo 2 do que no Grupo 1. No entanto, não foram encontradas diferenças significativas entre os grupos com relação às perguntas literais. Tal fato pode ser percebido analisando-se os dados apresentados na tabela 1, uma vez que os percentuais de respostas literais corretas foram semelhantes nos dois grupos de alunos. De um modo geral, os dados indicam que o nível de escolaridade influencia na capacidade de realizar inferências, pois os alunos do $6^{\circ}$ ano apresentaram maiores dificuldades para responder a essas perguntas, visto que o percentual de respostas corretas nesse grupo foi apenas ligeiramente superior a $50 \%$, enquanto no $7^{\circ}$ ano ultrapassou os $70 \%$.

Os valores de significância obtidos a partir das comparações feitas pelo teste estatístico em relação aos grupos são apresentados na tabela 4 .

Tabela 4 - Valores de significância do teste $T$ Student (amostras independentes) em relação aos grupos de participantes

\begin{tabular}{ccc}
\hline & Grupo 1 vs. Grupo 2 & \\
\hline Tipo de pergunta & sd & Valor-p \\
\hline $\begin{array}{c}\text { Literais } \\
\text { Inferenciais }\end{array}$ & 0,6015331 & 0,4352646 (ns) \\
& 0,8483731 & $0,04730002^{*}$ \\
\hline
\end{tabular}

Nota: Grupo 1: alunos do 6ํㅜ do Ensino Fundamental 
Grupo 2: alunos do $7^{\circ}$ ano do Ensino Fundamental

A tabela 5 apresenta 0 desempenho dos grupos em cada questão do instrumento, a fim de verificar quais perguntas suscitaram maior dificuldade ou facilidade para os participantes.

Tabela 5 - Porcentagem de acerto para cada pergunta do questionário por grupo de participantes

\begin{tabular}{ccccccc}
\hline Grupos (n=20) & P1 & P2 & P3 & P4 & P5 & P6 \\
\hline Grupo 1 & $15 \%$ & $70 \%$ & $90 \%$ & $55 \%$ & $85 \%$ & $85 \%$ \\
Grupo 2 & $35 \%$ & $70 \%$ & $90 \%$ & $85 \%$ & $95 \%$ & $90 \%$ \\
\hline
\end{tabular}

Nota: Grupo 1: alunos do 6ํㅜ do Ensino Fundamental

Grupo 2: alunos do $7^{\circ}$ ano do Ensino Fundamental

A partir dos dados da tabela 5, observa-se que a pergunta 1 ocasionou um menor percentual de respostas corretas em ambos os grupos (15\% e 35\%, respectivamente). Uma possível explicação para esse desempenho resulta da própria estratégia narrativa utilizada pelo autor do texto. Na crônica, temos a presença de um narrador testemunha que nos conta uma história que ouviu de um conhecido. Durante todo o texto, há dois planos que se alternam: a narrativa que versa sobre a relação entre o homem e seu cachorro, contada em $3^{\underline{a}}$ pessoa, e a narrativa sobre a conversa entre o dono do cachorro e o narrador, contada em $1^{\underline{a}}$ pessoa. Essa constante mudança no foco narrativo do texto justificaria a dificuldade demonstrada pelos participantes para compreender quem, de fato, está narrando a história.

As perguntas 2 e 3 exigiam a recuperação de informações explicitamente expressas no texto. A questão 3 apresentou um elevado número de respostas corretas nos dois grupos analisados (90\%). A questão 2, no entanto, apresentou um percentual inferior (70\%). Esses resultados podem ser explicados tendo em vista o modo como as informações requeridas pelas perguntas são apresentadas no texto. Embora ambas as perguntas tenham um caráter literal, há uma distinção entre elas. Na questão 3, a resposta para a pergunta encontra-se em uma só frase do texto. Na questão 2, por sua vez, a resposta encontra-se em diversas frases e partes do texto, sendo necessário juntar as informações para obter uma resposta completa, o que torna a questão mais difícil. Esse aspecto explicaria a diferença no percentual de acerto nessas questões.

$\mathrm{Na}$ questão 4, o desempenho dos dois grupos apresentou diferenças significativas $(p<0,05)$. É importante destacar que essa pergunta refere-se ao desfecho da história que é construído a partir de informações implícitas, cuja compreensão depende essencialmente da realização de inferências. Essa inferência é o que causa o humor da crônica e é a chave para sua compreensão. Os dados mostraram que os alunos com maior nível de escolaridade foram mais hábeis na realização da inferência. Uma possível explicação é que, ao não encontrarem no texto informações literalmente expressas sobre os eventos, os participantes com menor escolaridade tendiam a apoiar suas conclusões exclusivamente em seu conhecimento prévio, oferecendo respostas desautorizadas que extrapolam o sentido do texto, ao mencionar personagens que não foram citados. Os alunos com maior escolaridade, por sua vez, foram capazes de relacionar seus conhecimentos prévios às proposições do texto e, assim, realizar a inferência necessária para a compreensão do desfecho da história.

A resposta para a questão 5 , assim como para a questão 3 , exigia a localização de uma informação explícita no texto, a qual se encontrava em apenas uma frase. Sendo assim, os participantes dos dois grupos não tiveram dificuldade para encontrar a resposta correta, como pode ser observado pelos altos percentuais obtidos $(85 \%$ e $90 \%$, respectivamente).

O último item do questionário solicitava que os alunos relacionassem o título do texto os fatos narrados na história, justificando o porquê de a crônica intitular-se Prova Falsa. A inferência aqui realizada contribui para estabelecer a coerência global do texto. Nessa questão, os participantes de ambos os grupos apresentaram percentuais altos de 
respostas corretas (85\% e 95\%, respectivamente). É importante destacar que essa resposta relacionava-se à pergunta 4, que questionava os alunos sobre quem seria o autor do pipi no vestido da esposa do dono do cachorro, uma vez que se sabe, pelo que é contado na história, não ter sido o cão quem praticara tal ação. Nesse caso, é interessante observar a diferença no desempenho dos alunos do $6^{\circ}$ ano nas duas questões mencionadas. Enquanto na questão 6 esses participantes conseguiram um percentual alto de respostas corretas (85\%), na questão 4, o percentual foi consideravelmente inferior (55\%). Isso mostra que, embora tenham conseguido compreender que o pipi foi uma prova falsa usada contra o cachorro, o que justifica o título da crônica, alguns alunos não foram capazes de realizar a inferência que apontava o dono do cão como autor dessa ação, atribuindo a responsabilidade a outro personagem. Esse desempenho, no entanto, não foi observado entre os alunos do $7^{\circ}$ ano, que apresentaram percentuais semelhantes nas duas questões (85\% e 90\%, respectivamente).

Para compreender a dificuldade encontrada pelos alunos do $6^{\circ}$ ano faz-se necessário analisar a natureza da inferência requerida em cada questão. A inferência prevista pela questão 6 decorre de relações causais entre proposições do texto, no caso entre o título e o desfecho da história. Para responder à pergunta, o leitor precisa apoiar-se na informação implícita no texto. No texto, não há menção explícita à prova falsa mencionada no título, o leitor precisa acrescentar "porque" entre as duas informações: a prova é falsa porque o pipi não era do cachorro. A questão 4, por sua vez, exige uma inferência que decorre de informações que são acrescentadas com base na relação entre os conhecimentos prévios do leitor e as proposições do texto. Assim, para realizar a inferência, o leitor deverá acionar seu conhecimento prévio sobre as circunstâncias em que uma pessoa sente remorso, de modo a relacionar o motivo do remorso à autoria da ação questionada na pergunta.

Esses resultados sugerem que a natureza da pergunta inferencial apresentada exerce influência no estabelecimento de inferências e que inferências baseadas em informações intratextuais são mais facilmente realizadas do que as baseadas em informações extratextuais, especialmente no caso de alunos com menor grau de escolaridade.

\section{Considerações finais}

A presente pesquisa, impulsionada pelas dificuldades em leitura evidenciadas pelos estudantes brasileiros, buscou verificar como alunos do $6^{\circ}$ e $7^{\circ}$ anos do Ensino Fundamental compreendem informações literais e inferenciais em um texto narrativo.

Analisando-se cada grupo individualmente, os resultados revelam que as perguntas inferenciais foram mais difíceis do que as perguntas literais tanto para os alunos do $6^{\circ}$ quanto do $7^{\circ}$ ano, sugerindo que realizar inferências é uma tarefa complexa para alunos nos níveis de escolaridade investigados.

Comparações mostraram não haver diferenças entre os grupos de alunos em relação às perguntas literais. Isso decorre do fato de os alunos de ambos os grupos serem bastante hábeis em recuperar informações literais de um texto. Esse mesmo padrão de desempenho, no entanto, não foi observado quando a tarefa exigia o estabelecimento de inferências, uma vez que o percentual de respostas corretas dos alunos do $7^{\circ}$ ano às perguntas inferenciais foi superior ao percentual dos alunos do 6 ano, indicando que esta capacidade evolui com a progressão escolar.

Com relação às perguntas literais, os resultados demonstram que 0 modo como a informação literal é apresentada no texto influencia no seu processamento. Perguntas que solicitavam informações literais apresentadas em uma mesma frase foram mais facilmente recuperadas. Contudo, perguntas que exigiam a união de informações apresentadas ao longo texto mostraram-se mais difíceis para os grupos analisados.

Com relação às inferências, os resultados indicam que a natureza da inferência também influencia no desempenho dos participantes. Inferências baseadas em relações entre informações 
intratextuais que podem ser identificadas no texto são mais facilmente realizadas pelos alunos do $6^{\circ}$ ano do que aquelas que envolvem informações extratextuais. Este padrão de resultados não foi observado nos alunos do $7^{\circ}$ ano que apresentaram um desempenho mais homogêneo. Talvez isso ocorra porque os alunos menos escolarizados, ao não encontrarem no texto informações literalmente expressas sobre os eventos, apoiam suas conclusões exclusivamente em seu conhecimento prévio, oferecendo respostas desautorizadas que extrapolam o sentido do texto.

O presente estudo trouxe para discussão a forma como as diferentes informações de um texto, literais e inferenciais, são processadas por alunos do Ensino Fundamental, oferecendo subsídios que podem ser úteis no desenvolvimento dessas habilidades no contexto escolar. Os dados obtidos podem indicar um caminho para um trabalho pedagógico que estimule os alunos a analisar e relacionar as diferentes informações de um texto, fazendo-os perceber que a resposta a uma pergunta não é sempre dada explicitamente em uma frase do texto, mesmo em perguntas de caráter literal, que podem exigir o processamento de várias informações do texto.

Pesquisas futuras precisam esclarecer ainda mais as relações aqui estabelecidas, investigando-as em alunos de outras faixas etárias e níveis de escolaridade. Além disso, seria importante investigar como essas informações são processadas em outros tipos de textos, levantando dados que possam ser comparados aos resultados já obtidos nessa pesquisa com relação ao texto narrativo.

\section{Referências}

CASTRO, J. S. e PEREIRA, V. W. Leitor e texto: a preditibilidade faz a interação. Calidoscópio. São Leopoldo: Unisinos, v. 2, n. 1, 2004.

GOODMAN, K. S. Reading, a psycholinguist guessing game. In: SINGER, H.; RUDDELL, R. Theoretical models and processes of reading. Newark: International Reading Association, p. 497 - 508, 1976.

KATO, M. A. O aprendizado da leitura. São Paulo: Martins Fontes, 2007.

KINTSCH, W. Comprehension: a paradigm for cognition. Cambridge: Cambridge University Press, 1998.

KLEIMAN, A. Texto e leitor: aspectos cognitivos da leitura. Campinas: Pontes, 2013.

LEFFA, V. J. Aspectos da leitura: uma perspectiva psicolinguística. Porto Alegre: Sagra-Luzzato, 1996.

MARCUSCHI, L. A. Produção textual, análise de gêneros e compreensão. São Paulo: Parábola Editorial, 2008.

SCLIAR-CABRAL, L. Processamento bottom-up na leitura. Revista de Estudos Linguísticos Veredas: Psicolinguística. Juiz de Fora: UFJF, v. 12, n. 2, p. 24-33, 2008.

SMITH, F. Compreendendo a leitura: uma análise psicolinguística da leitura e do aprender a ler. Porto Alegre: Artes Médicas, 2003.

SOLÉ, I. Estratégias de leitura. Porto Alegre: Artmed, 1998.

SOUSA, L. B. de e HÜBNER, L. C. Desafios na avaliação da compreensão leitora: demanda cognitiva e leiturabilidade textual. Revista Neuropsicologia Latinoamericana. v. 7, n. 1, p. 3446, 2015.

SPINILLO, A. G. A dimensão social, linguística e cognitiva da compreensão de textos: considerações teóricas e aplicadas. In: MOTA, M. P. da e SPINILLO, A. G. (Orgs.). Compreensão de textos. São Paulo: Casa do Psicólogo, p. 171-198, 2013.

\section{COMO CITAR ESSE ARTIGO}

BARETTA, Danielle; WANNMACHER PEREIRA, Vera. COMPREENSÃO LITERAL E INFERENCIAL EM ALUNOS DO ENSINO FUNDAMENTAL. Signo, Santa Cruz do Sul, v. 43, n. 77, jul. 2018. ISSN $1982-2014$. Disponível em: <https://online.unisc.br/seer/index.php/signo/article/view/11533>. Acesso em: doi: http://dx.doi.org/10.17058/signo.v43i77.11533. 


\section{Anexo}

Prova falsa

Stanislaw Ponte Preta

Quem teve a ideia foi o padrinho da caçula ele me conta. Trouxe o cachorro de presente e logo a família inteira se apaixonou pelo bicho. Ele até que não é contra isso de se ter um animalzinho em casa, desde que seja obediente e com um mínimo de educação.

- Mas o cachorro era um chato - desabafou.

Desses cachorrinhos de raça, cheio de nhémnhém-nhém, que comem comidinha especial, precisam de muitos cuidados, enfim, era realmente um chato. $E$, como se isto não bastasse, implicava com o dono da casa.

- Vivia de rabo abanando para todo mundo, mas, quando eu entrava em casa, vinha logo com aquele latido fininho e antipático de cachorro de gente rica.

Ainda por cima era puxa-saco. Quando cruzavam num corredor ou qualquer outra dependência da casa, o desgraçado rosnava de modo ameaçador, mas, quando a patroa estava perto, abanava o rabinho, fingindo-se amigo dele.

- Quando eu reclamava, dizendo que o cachorro era um cínico, minha mulher brigava comigo, dizendo que nunca houve cachorro fingido e eu é que insistia em implicar com o "pobrezinho".

Num rápido balanço era capaz de assinalar: o cachorro comeu oito meias suas, roeu a manga de um paletó, rasgou diversos livros. A vida na casa estava ficando insuportável. Estava vendo a hora em que se divorciava por causa daquele bicho cretino. Tentou mandá-lo embora umas vinte vezes e era uma choradeira das crianças e da mulher.

Só venceu a guerra com o cachorro graças à má educação do adversário. O cãozinho começou a fazer pipi onde não devia. Várias vezes repreendido, continuou com o feio comportamento. Fez diversas vezes no tapete da sala. Fez duas na boneca da filha maior. Quatro ou cinco vezes nos brinquedos da caçula. Tudo culminou com o pipi que fez no vestido novo da mulher.

- Depois disso mandaram o cachorro embora? - perguntei.

- Sim, mandaram. Mas fiz questão de dá-lo de presente a um amigo que adora cachorros. Está levando um vidão na nova residência.

Mas fiz questão de dá-lo de presente a um amigo que adora cachorros. Está levando um vidão na nova residência.

- Ué... mas você não o detestava? Como arranjou essa moleza pra ele?

- Problema de consciência - explicou - $\mathrm{O}$ pipi não era dele.

E suspirou cheio de remorso.

Adaptado de: O melhor de Stanislaw Ponte Preta. Rio de Janeiro: José Olympio, 2011, p. 186188. 